\title{
Surgical Outcomes Open versus Laparoscopic Repair for Inguinal Hernia
}

\author{
Dr. Abid Ali Mirza ${ }^{1}$, Dr. Alfred J. Augustine ${ }^{2}$, Dr. Shibumon M.M ${ }^{3}$ \\ ${ }^{1,2,3}$ (Department of General Surgery, Kasturba Medical College Mangalore/ Manipal University,India)
}

\begin{abstract}
Repair of inguinal hernia is one of the commonest surgical procedures worldwide. Since the era of tension free repair using synthetic mesh, the basic tenets of hernia repair has changed little. Currently there are two methods of mesh placement: open method or laparoscopic method. Although a number of clinical studies have explored the potential benefits and drawbacks of open and laparoscopic repair for inguinal hernia, no one procedure has emerged as having a clear benefit over the other. This study endeavors to reach a clear conclusion as to which is the most suitable procedure, with a special emphasis on the influence of the surgeon's experience on the outcome.

A combined Prospective and retrospective Cohort study was carried out in KMC Hospitals, Mangalore. The sample size was two hundred for each arm; patients aged 18 and above without factors pre-disposing to recurrence were included in the study. The subjects were followed up for a period of one year at the end of which primary outcome assessed was recurrence. A number of secondary outcomes such as hematoma, persistent pain and return to regular activity were also assessed. The study concluded that the rate of recurrence in the laparoscopic arm was higher (5\%) compared to the open arm $(2.5 \%)$. However, we observed that $90 \%$ of the recurrences in the laparoscopic arm were at the hands of surgeons with less than five years experience in laparoscopic surgery which was statistically highly significant $(P$ value $=0.00)$. In the open arm however, the surgeons' experience did not alter the outcome significantly $(P$ value $=0.341)$. Thus, laparoscopic repair for inguinal hernia is a safe alternative in the hands of experienced laparoscopic surgeons.
\end{abstract}

Keywords: Lichenstein Herniolpasty, Transabdominal Pre-Peritoneal repair (TAPP), Totally Extra peritoneal repair (TEP)

\section{Introduction}

Repair of inguinal hernia is one of the commonest surgical procedures worldwide. Since the era of tension free repair using synthetic mesh, the basic tenets of hernia repair have changed little. Currently there are two methods of mesh placement: open method and minimally invasive laparoscopic method. Although a large number of clinical studies have explored the potential benefits and drawbacks of open and laparoscopic repair, no one procedure has emerged as having a clear benefit over the other. In the Neumayer, Champault and MRC study the incidence of recurrence was higher in the laparoscopic arm, while the Chung, Grant and McComrack studies showed no significant difference. ${ }^{[1-5]}$ The Liem study alone showed a higher recurrence rate in the open group. ${ }^{[6]}$

Benefits claimed in favour of the open method are reduced incidence of recurrence, easy to perform, with shorter operating time. Additionally it has less risk of serious complications, with shorter learning curve and can be performed under local anesthesia. The laparoscopic approach has an advantage of less post op pain, faster recovery and reduced hospital stay. Moreover, the incidence of complications such as hematoma, seroma and persistent pain are lesser. However, serious complications have also been reported, such as nerve injuries, major vascular injuries, bowel obstruction, and bladder injury. The laparoscopic method has a steep learning curve and is difficult to master and is relatively expensive.

Given the large number of hernias repaired, there is an urgent need to lift this cloud of ambiguity over which procedure is most suitable. This study therefore, endeavors to answer this question definitively and reach a clear conclusion. The subjects in both groups were closely followed up and the results compared. Unlike most studies on this subject, a greater emphasis was made on the experience of the operating surgeon and its bearing on the outcome.

\section{Methods and Materials}

A combined prospective and retrospective Cohort study was conducted at Kasturba Medical College Hospitals, Mangalore from January 2012 to October 2013. The sample size was two hundred for each study arm with power of eighty per cent. Half the subjects in each arm were studied retrospectively and the other half prospectively. 
All patients above the age of 18 years with a clinical diagnosis of inguinal hernia for whom surgical management was judged appropriate were included in the study. Patients with factors predisposing to recurrence such as chronic cough, ascities, previous hernia surgery were excluded from the study.

The outcomes were assessed post operatively at 2 weeks, 3 months and 1year intervals. The primary outcome assessed was recurrence. A number of secondary outcomes such as incidence of seroma, hematoma, wound infection, mesh infection, length of hospital stay, persistent pain and time to return to regular activity were also measured. The surgeons' experience was taken into account by dividing them into those with experience more than and less than five years experience in laparoscopic surgery.

Comparisons were carried out by the Pearson $\chi^{2}$ test or Fisher exact test where appropriate for categorical data and Student $t$ test for parametric data. Qualitative parameters were calculated using Student- $t$ test. Quantitative parameters such as incidence of hematoma, recurrence, etc were calculated using Chi square test. Statistical analysis was performed using the Statistical Package for Social Science (SPSS, Inc., Chicago IL.)

\section{Results \& Observations}

A total of 400 patients were followed up for a period of 1 year, of which 396 were males and 4 females. The techniques of mesh placement compared were the primary open onlay repair (Lichenstein Tension free Hernioplasty) and Laparoscopic approaches i.e Totally extraperitoneal repair and Transabdominal Preperitoneal repair. The patients underwent surgeries in their respective units and followed up post operatively.

The results of our study show a recurrence rate of $5 \%$ in the laparoscopic arm and $2.5 \%$ in the open arm. Studies such as the Neumayer trial had a recurrence rate of $10.1 \%$ and $4.1 \%$ in the laparoscopic and open groups while in the Champault study it was $6 \%$ and $2 \%{ }^{[1,2]}$. The comparison of the recurrence rate was not statistically significant $(\mathrm{P}$ value $=0.188$ ). The McComrack and Grant studies also arrived at similar conclusions. $[4,5]$

On further analysis of the results we observed that $90 \%$ of the recurrences in the laparoscopic arm were at the hands of surgeons with less than five years experience in laparoscopic surgery. This was statistically highly significant $(\mathrm{P}$ value $=0.00)$. In the open arm however, the rate of recurrence in the two groups were $60 \%$ and $40 \%$ respectively. Hence, the surgeons' experience did not alter the outcome significantly (P value $=0.341)$ in the open arm. The Neumayer trial also reported similar findings. ${ }^{[1]}$ Table 1 illustrates the comparison between the various outcomes with respect to surgeons' outcomes.

According to some studies the learning curve for laparoscopic hernia repair plateaued after 30 cases where as others reported a recurrence rate of $10 \%$ among surgeons who had performed less than 250 surgeries, with rates approaching open repair after 250 surgeries. ${ }^{[1,6,7]}$ This reflects the steep learning curve involved in laparoscopic surgery and validates the need for better supervision and standardizing laparoscopic training.

The incidence of other complications such as seroma $(\mathrm{P}$ value $=0.025)$, persistent pain $(\mathrm{P}$ value $=$ $0.035)$, mesh infection $(\mathrm{P}$ value $=0.025)$ was significantly higher in the less experienced group of surgeons in both arms.

The incidence of persistent pain was a significant finding of this study. The incidence in the laparoscopic arm was $3.5 \%$ while the open arm showed a significantly higher rate at $16.5 \%$, $(\mathrm{P}$ value $=0.00)$. The incidence varies among studies, ranging between $0 \%$ and $62.9 \%$, with $10 \%$ of patients fitting in the moderate to severe pain group ${ }^{[8-12]}$. However, only $2 \%-4 \%$ of the patients are adversely affected by chronic groin pain in their everyday life.

Inguinodynia following Lichtenstein tension-free hernia repair is significant, considering the volume of the operations performed worldwide ${ }^{[13]}$. The ilioinguinal, iliohypogastric and genitofemoral nerves are commonly involved. Nerve entrapment during mesh fixation and removal of the cremasteric covering of the cord are postulated to cause damage to the nerves. 


\begin{tabular}{|c|c|c|c|c|c|c|}
\hline \multirow{2}{*}{\multicolumn{2}{|c|}{ gery }} & \multicolumn{2}{|c|}{$x 2$ value and $p$ value } & & \multicolumn{2}{|c|}{ Fishers exact test } \\
\hline & & & & & & \\
\hline \multirow[t]{2}{*}{ Age*Surgeon Experience } & Lap & 3.328 & .767 & & $\cdot$ & \\
\hline & Open & 9.579 & .144 & & & \\
\hline \multirow[t]{2}{*}{ Sex* Surgeon Experience } & Lap & & & & .395 & \\
\hline & Open & & & & .490 & \\
\hline \multirow[t]{2}{*}{ Disease* Surgeon Experience } & Lap & 6.522 & .038 & Siç & & \\
\hline & Open & 4.906 & .086 & & & \\
\hline \multirow[t]{2}{*}{ Recurrence* Surgeon Experience } & Lap & 18.495 & .000 & HS & & \\
\hline & Open & .905 & .341 & & & \\
\hline \multirow[t]{2}{*}{ Seroma*Surgeon Experience } & Lap & 5.017 & .025 & Siç & & \\
\hline & Open & 4.759 & .029 & Siç & & \\
\hline \multirow[t]{2}{*}{ Hematoma *Surgeon Experience } & Lap & .032 & .857 & & & \\
\hline & Open & 1.673 & 196 & & & \\
\hline \multirow[t]{2}{*}{ Wound Infection * Surgeon Experience } & Lap & .254 & .615 & & & \\
\hline & Open & .005 & .946 & & & \\
\hline \multirow[t]{2}{*}{ PersistentPain * Surgeon Experience } & Lap & & & & .069 & \\
\hline & Open & 4.268 & .039 & Siç & & \\
\hline \multirow[t]{2}{*}{ Mesh Infection* Surgeon Experience } & Lap & 5.017 & .025 & Siç & & \\
\hline & Open & 1.714 & .190 & & & \\
\hline \multirow{2}{*}{$\begin{array}{l}\text { Persistent Numbness * Surgeon } \\
\text { Experience }\end{array}$} & Lap & & & & .018 & Sic \\
\hline & Open & 1.460 & .227 & & & \\
\hline \multirow[t]{2}{*}{ Length of Stay * Surgeon Experience } & Lap & .011 & .916 & & & \\
\hline & Open & .314 & .575 & & & \\
\hline \multirow{2}{*}{$\begin{array}{l}\text { Return to Activities * Surgeon } \\
\text { Experience }\end{array}$} & Lap & 4.739 & .094 & & & \\
\hline & Open & 4.350 & .226 & & & \\
\hline
\end{tabular}

Traditional teaching has always been to preserve the nerve, but recent studies have looked into the intentional severance based on the concept of "no nerve, no pain" ${ }^{[14]}$. RCTs comparing deliberate Ilio Inguinal Nerve neurectomy vs preservation have shown conflicting results. Two RCTs have shown significant reduction in chronic groin pain post-neurectomy, whereas two other studies concluded there was no influence of neurectomy on pain rates ${ }^{[15-18]}$.

In the laparoscopic repair apart from the above mentioned nerves the lateral femoral cutaneous and femoral nerve may also be involved. Entrapment of the lateral femoral cutaneous nerve in the so called 'triangle of pain' is the most common injury in TEP resulting in meralgia paresthetica. Guidelines recommend limited dissection, staying above the iliopubic tract and not straying too far lateral to the internal ring while fixing the mesh.

The technique of mesh placement therefore needs closer attention by the operating the surgeon and better understanding of the anatomy may help in reducing the incidence of this debilitating complication.

Similar to findings reported by other studies, the length of hospital stay was significantly shorter in the experienced laparoscopic surgeon group by 1.3 days, $P$ value 0.00 . Furthermore, the recovery from surgery after laparoscopic surgery was significantly faster, approximately 5.4 days with $\mathrm{P}$ value $=0.00$. The open group experienced increased immediate post operative pain which led to slower recovery and resumption of regular activities. Hence, laparoscopic hernia repair by an experienced surgeon shortens the hospital stay significantly with faster recovery, thereby reducing the economic burden and partially compensates for the increased cost of laparoscopic surgery.

\section{Conclusion}

From the results of this study we find the outcomes of laparoscopic inguinal hernia are comparable with open repair. Laparoscopic repair has an advantage of less post operative pain, decreased hospital stay, faster recovery and improved cosmesis. It may soon become the procedure of choice not only for bilateral and recurrent hernias but also for primary, unilateral hernias.

The open repair has a definite advantage over laparoscopic repair financially; however the decreased hospital stay and faster recovery may reduce the economic burden of laparoscopic surgery to some extent. The operative cost may be reduced further by employing cheaper reusables and optimal use of resources.

The issue of the steep learning curve for laparoscopic surgery should be addressed with better supervision and standardization of training in laparoscopy. Strict adherence to the protocols of laparoscopic surgery will go a long way in reducing the intra operative complications and improve post operative outcomes.

The open repair remains a good option especially for older, high risk patients and for the underprivileged as it has a low rate of recurrence, easy to perform, inexpensive and can be done under local anesthesia. However, the trend in surgery today is in favour of minimally invasive surgery and rightfully so as this study proves. 


\section{References}

[1]. Leigh Neumayer, M.D., Anita Giobbie-Hurder, M.S., Olga Jonasson, M.D.et al; N Engl J Med 2004; 350:1819-1827

[2]. Champault GG, Rizk N, Catheline JM, Turner R, Boutelier P. Inguinal hernia repair: totally preperitoneal laparoscopic approach versus Stoppa operation: randomized trial of 100 cases. Surg Laparosc Endosc. 1997 Dec;7 (6):445-50. PubMed PMID: 9438623.

[3]. MRC Laparoscopic Hernia Trial Group, Laparoscopy versus open repair of Groin hernia: A Randomised Comparison. Lancet 1999; 345: 185-90.

[4]. Grant AM. Laparoscopic versus open groin repair: Metanalysis of randomised trials based on individual patient data. The EU Hernia colibrate. Hernia 2002; 6: 2-10.

[5]. McCormack K, Scott NW, Go PM, Ross S, Grant AM; EU Hernia Trialists Collaboration. Cochrane Database Syst Rev. 2003 ;( 1):CD001785. Review.

[6]. Liem MSL, van Steensel CJ, Boelhouwer RU, et al. The learning curve for totally extraperitoneal laparoscopic inguinal hernia repair. Am J Surg1996;171:281-285.

[7]. Wright D, O'Dwyer PJ. The learning curve for laparoscopic hernia repair. Semin Laparosc Surg 1998;5:227-232

[8]. Poobalan AS, Bruce J, King PM, Chambers WA, Krukowski ZH, Smith WC. Chronic pain and quality of life following open inguinal hernia repair. Br J Surg 2001; 88: 1122-1126.

[9]. Courtney CA, Duffy K, Serpell MG, O'Dwyer PJ. Outcome of patients with severe chronic pain following repair of groin hernia. Br J Surg 2002; 89: 1310-1314

[10]. Bay-Nielsen M, Perkins FM, Kehlet H. Pain and functional impairment 1 year after inguinal herniorrhaphy: a nationwide questionnaire study. Ann Surg 2001; 233: 1-7

[11]. Cunningham J, Temple WJ, Mitchell P, Nixon JA, Preshaw RM, Hagen NA. Cooperative hernia study. Pain in the postrepair patient. Ann Surg 1996; 224: 598-602

[12]. Callesen T, Bech K, Kehlet H. Prospective study of chronic pain after groin hernia repair. Br J Surg 1999; 86: 1528-1531

[13]. Kehlet H, Jensen TS, Woolf CJ. Persistent postsurgical pain: Risk factors and prevention. Lancet 2006; 367: 1618-1625

[14]. Wantz GE. Hernioplasty controversy. J Am Coll Surg 1998; 186: 372-373

[15]. Mui WL, Ng CS, Fung TM, Cheung FK, Wong CM, MaTH, Bn MY, Ng EK. Prophylactic ilioinguinal neurectomyin open inguinal hernia repair: a double-blind randomized controlled trial. Ann Surg 2006; 244: 27-33

[16]. Malekpour F, Mirhashemi SH, Hajinasrolah E, Salehi N, Khoshkar A, Kolahi AA. Ilioinguinal nerve excision in open mesh repair of inguinal hernia--results of a randomized clinical trial: simple solution for a difficult problem? Am J Surg 2008; 195: 735-740

[17]. Ravindran R, Bruce J, Debnath D, Poobalan A, King PM. A United Kingdom survey of surgical technique and handling practice of inguinal canal structures during hernia surgery. Surgery 2006; 139: 523-526

[18]. Picchio M, Palimento D, Attanasio U, Matarazzo PF, Bambini C, Caliendo A. Randomized controlled trial of preservationor elective division of ilioinguinal nerve on open inguinal hernia repair with polypropylene mesh. Arch Surg 2004; 139: 755-758. 